Bath, but I was not fortunate in finding any similar shales at the other coal-pits visited. Remains of Entomostraca were, however, tolerably abundant at one or two localities, and I have little doubt would yield a rich harvest to any local investigator. Having submitted the few specimens I obtained to Professor Rupert Jones, that gentleman has kindly determined them. From the bituminous shale of Mr. Farrar's pit at Nailsea ; Estheria striata, var. Beinertiana (Mon. Foss. Estheriæ, Pl. I., Fig. 13), with intercostal spaces distinctly wide, but not shewing ornament; also an imperfect cast of Beyrichia arcuata? From the roof of the white seam of Youngwood pit, Nailsea, were obtained Kirkbya costata, not in good condition, and partly-imbedded well preserved specimens, of a species of Cythere, as well as some indeterminable casts. In the shale, about 200 feet above the white seam of the last pit, was observed an Ostracod imbedded with its surface downwards, closely resembling Cythere fabulina. Numerous seed-vessels (sporangia) were likewise observed in the Coal-shales of Bedminster and Yate, referable probably to Flemingites or Lepidodendron (see GroL. MAG., 1865, Vol. II., p. 433, Plate XII).

In a letter, just received from Mr M'Murtrie, he states that, "at Radstock no animal-remains have been found in the Coal-measures, but that at Camerton several specimens of bivalve shells (Anthracosia?) and two specimens of Limulus have been found by $\mathrm{Mr} \mathrm{E}$. Feare."

J. M.

\title{
INOTICFS OF MEMMOIRS.
}

\section{I.-ON THE ANIMALS WHICH ARE MOST NEARLY INTERMEDILTE} BetWeEN Birds and Reptiles. ${ }^{1}$

By Professor Huxley, LL.D., F.R.S.

THOSE who hold the doctrine of Evolution (and I am one of 1 them) conceive that there are grounds for believing that the world, with all that is in it and on it, did not come into existence in the condition in which we now see it, nor in anything approaching that condition.

On the contrary, they hold that the present conformation and com. position of the earth's crust, the distribution of land and water, and the infinitely diversified forms of animals and plants which constitute its present population, are merely the final terms in an immense series of changes which have been brought about, in the course of immeasurable time, by the operation of causes more or less similar to those which are at work at the present day.

Perhaps this doctrine of Evolution is not maintained consciously, and in its logical integrity, by a very great number of persons. ${ }^{2}$ But

I Being a Lecture delivered at the Royal Institution of Great Britain, on Friday, February 7, 1868.

${ }_{2}$ The only complete and systematic statement of the doctrine with which $I$ am acquainted is that contained in Mr. Herbert Spencer's "System of Philosophy," a work which should be carefully studied by all who desire to know whither scientific thonght is tending. 
many hold particular applications of it without committing themselves to the whole; and many, on the other hand, favour the general doctrine without giving an absolute assent to its particular applications.

Thus, one who adopts the nebular hypothesis in Astronomy, or is a Uniformitarian in Geology, or a Darwinian in Biology, is, so far, an adherent of the doctrine of Evolution.

And, as I can testify from personal experience, it is possible to have a complete faith in the general doctrine of Evolution and yet to hesitate in accepting the Nebular, or the Uniformitarian, or the Darwinian hypotheses in all their integrity and fullness. For many of the objections which are brought against these various hypotheses affect them only, and even if they be valid, leave the general doctrine of Evolution untouched.

On the other hand, it must be admitted that some arguments which are adduced against particular forms of the doctrine of Evolution; would very seriously affect the whole doctrine if they were proof against refutation.

For example, there is an objection which I see constantly and confidently urged against Mr. Darwin's views, but which really strikes at the heart of the whole doctrine of Evolution, so far as it is applied to the organic world.

It is admitted on all sides that existing animals and plants are marked out by natural intervals into sundry very distinct groups :Insects are widely different from Fish-Fish from Reptiles-Reptiles from Mammals-and so on. And out of this fact arises the very pertinent objection,-How is it, if all animals have proceeded by gradual modification from a common stock, that these great gaps exist?

We, who believe in Evolution, reply, that these gaps were once non-existent ; that the connecting forms existed in previous epochs of the world's history, but that they have died out.

Naturally enough, then, we are asked to produce these extinct forms of life. Among the innumerable fossils of all ages which exist, we are asked to point to those which constitute such connecting forms.

Our reply to this request is, in most cases, an admission that such forms are not forthcoming, and we account for this failure of the needful evidence by the known imperfection of the geological record. We say that the series of formations with which we are acquainted is but a small fraction of those which have existed, and that between those which we know there are great breaks and gaps.

I believe that these excuses have very great force; but I cannot smother the uncomfortable feeling that they are excuses.

If a landed proprietor is asked to produce the title-deeds of his estate, and is obliged to reply that some of them were destroyed in a fire a century ago, that some were carried off by a dishonest attorney, and that the rest are in a safe somewhere, but that he really cannot lay his hands upon them; he cannot, I think, feel pleasantly secure, though all his allegations may be correct and his ownership indisputable. But a doctrine is a scientific estate, and the holder must 
always be able to produce his title-deeds, in the way of direct evidence, or take the penalty. of that peculiar discomfort to which I have referred.

You will not be surprised, therefore, if I take this opportunity of pointing out that the objection to the doctrine of Evolution, drawn from the supposed absence of intermediate forms in the fossil state, certainly does not hold good in all cases. In short, if I cannot produce the complete title-deeds of the doctrine of animal Evolution, I am able to show a considerable piece of parchiment evidently belonging to them.

To superficial observation no two groups of beings ean appear to be more entirely dissimilar than Reptiles and Birds. Placed side by side, a Humming-bird and a Tortoise, an Ostrich and a Crocodile, offer the strongest contrast, and a Stork seems to have little but animality in common with the Snake it swallows.

Careful investigation has shown, indeed, that these obvious differences are of a much more superficial character than might have been suspected, and that Reptiles and Birds do really agree much more closely than Birds with Mammals, or Reptiles with Amphibians. But still, " though not as wide as a church-door or as deep as a well," the gap between the two groups, in the present world, is considerable enough.

Without attempting to plunge you into the depths of anatomy, and confining myself to that osseous system to which those who desire to compare extinct with living animals are almost entirely restricted, I may mention the following as the most important differences between all the Birds and Reptiles which at present exist.

1. The pinion of a Bird, which answers to the hand of a man or to the forepaw of a Reptile, contains neither more nor fewer than three fingers. These answer to the thumb and the two succeeding fingers in man, and have their metacarpals connected together by firm bony union, or anchylosed. Claws are developed upon the ends of at most two of the three fingers (that answering to the thumb and the next), and are sometimes entirely absent.

No Reptile with well-developed forelimbs has so few as three fingers; nor are the metacarpal bones of these ever united together; nor do they present fewer than three claws at their terminations.

2. The breast-bone of a Bird becomes converted into membranebone, and ossification commences in it from at least two centres.

The breast-bone of no Reptile becomes converted into membranebone, nor does it ever ossify from several distinct centres.

3. A considerable number of caudal and lumbar, or dorsal, vertebræ unite together with the proper sacral vertebræ of a Bird to form its " sacrum." In Reptiles the same region of the spine is constituted by the one or two sacral vertebræ.

4. In Birds the haunch-bone (ilium) extends far in front of, as well as behind, the acetabulum; the ischia and pubes are directed backwards, almost parallel with it and with one another; the ischia do not unite in the ventral middle line of the body. In Reptiles, on the contrary, the haunch-bone is not produced in front of the acetabulum; 
and the axes of the ischia and pubes diverge and lie more or less at right angles to that of the ilium. The ischia always unite in the middle ventral line of the body.

5. In all Birds the axis of the thigh-bone lies nearly parallel with the median plane of the body (as in ordinary Mammalia) in the natural position of the leg. In Reptiles it stands out at a more or less open angle with the median plane.

6. In Birds one half of the tarsus is inseparably united with the tibia, the other half with the metatarsal bone of the foot. This is not the case in Reptiles.

7. Birds never have more than four toes, the fifth being always absent. The metatarsal of the hallux, or great toe, is always short and incomplete above. The other metatarsals are anchylosed together, and unite witn one half of the tarsus, so as to form a single bone, which is called the tarsometatarsus. Reptiles with completely developed hind-limbs have at fewest four toes, the metatarsals of which are all complete and distinct from one another.

Although all existing Birds differ thus definitely from existing Reptiles, one comparatively small section comes nearer Reptiles than the others. These are the Ratite, or struthious birds, comprising the Ostrich, Rhea, Emu, Cassowary, Apteryx, and the but recently extinct (if they be really extinct) birds of New Zealand, Dinornis, etc., which attained gigantic dimensions. All these birds are remarkable for the small size of their wings, the absence of a crest or keel upon the breastbone, and of a complete furcula; in many cases, for the late union of the bones of the pinion, the foot, and the skull. In this last character in the form of the sternum, of the shoulder-girdle, and in some peculiarities of the skull, these birds are more reptilian than the rest; but the total amount of approximation to the reptilian type is but small, and the gap between Reptiles and Birds is but very slightly narrowed by their existence.

How far can this gap be filled up by a reference to the records of the life of past ages?

This question resolves itself into two :-

1. Are any fossil Birds more reptilian than any of those now living?

2. Are any fossil Reptiles more bird-like than living reptiles? And I shall endeavour to show that both these questions must be answered in the affirmative.

It is very instructive to note by how mere a chance it is we happen to know that a fossil bird, more reptilian in some respects than any now living, once existed.

Bones of birds have been obtained from rocks of very various dates in the Tertiary series without revealing any forms but such as would range themselves among existing families.

A few years ago the great Mesozoic formations had yielded only the few fragmentary ornitholites which have been discovered in the Cambridge Greensand, and which are insufficient for the complete determination of the affinities of the bird to which they belonged. 
However, the very fine calcareous mud of the ancient Oolitic seabottom which has now hardened into the famous Lithographic slate of Solenhofen, and has preserved innumerable delicate organisms of the existence of which we should otherwise have been, in all probability, totally ignorant, in 1861 revealed the impression of a feather to the famous palæontologist, Herman von Meyer. Von Meyer named the unknown bird to which this feather belonged Archoopteryx lithographica, and in the same year, the independent discovery by Dr. Häberlein of the precious skeleton of the Archoeopteryx itself, which now adorns the British Museum, ${ }^{1}$ demonstrated the chief characters of this very early bird. But it must be remembered that this feather and this imperfect skeleton are the sole remains of birds which have yet been obtained in all that great series of formations known as Wealden and Oolite, which partly lie above, partly below, and partly correspond with, the Solenhofen slates.

Though some palæontologists may be forced by a sense of consistency to declare that the class of birds was created in the sole person of Archoopteryx during the deposition of the Solenhofen slates, and disappeared during the Wealden, to be re-created in the Greensand, to vanish once more during the Cretaceous epoch and reappear in the Tertiaries, I incline to the hypothesis that many birds besides Archoeopteryx existed throughout all this period of time, and that we know nothing about them, simply because we do not happen to have hit upon those deposits in which their remains are preserved.

Now, what is this Archoopteryx like? Unfortunately, the skull is lost, but the leg and foot, the pelvis, the shoulder-girdle, and the feathers, so far as their structure can be made out, are completely those of existing ordinary birds.

On the other hand, the tail is very long, and more like that of a reptile than that of a bird in this respect. Two digits of the manus have curved claws, much stronger than those of any existing bird; and, to all appearance, the metacarpal bones are quite free and disunited.

Thus it is a matter of fact that, in certain particulars, the oldest known bird does exhibit a closer approximation to reptilian structure than any modern bird.

Are any fossil reptiles more bird-like than those which now exist?

As in the case of birds, the Tertiary formations yield no trace of reptiles which depart from the type of the existing groups. But otherwise than is true of birds, the newest of the Mesozoic formations, the Chalk, makes us acquainted with reptiles which, at first sight, seem to approach birds in a very marked manner. These are those flying reptiles, the Pterodactyles, which resemble the great majority of birds in the presence of air-cavities in their bones, in the wonderfully bird-like aspect of their coracoid and scapula, and in their broad sternum with its median crest. Furthermore, in some of the Pterodactyles, the premaxillæ and the symphysial part of the

1 The fossil has been described by Professor Owen in the "Philosophical Transactions " for 1863 .

ror. $\mathrm{V}, \mathrm{-NO} \mathrm{L}$. 
mandibles were prolonged into beaks, which appear to have been sheathed in horn, while the rest of each jaw was armed with teeth.

But horn-sheathed beaks are found in reptiles as well as in birds; the structure of the scapulo-coracoid arch and of the sternum, and the pneumaticity of the bones, vary greatly among birds themselves; and these characters of the Pterodactyles may be merely adaptive modifications.

On the other hand, the manus has four free digits, the three inner of which are strongly clawed, while the fourth is enormously prolonged, in total contrast to the abortion of the corresponding digit in birds. The pelvis is as wholly unlike that of birds as is the hindlimb and foot.

Thus it appears that Pterodactyles, among reptiles, approach birds much as Bats, among Mammals, may be said to do so. They are a sort of reptilian Bats ${ }^{1}$ rather than links between Reptiles and Birds, and it is precisely in those organs which, in birds, are the most characteristically ornithic, the manus and the pes, that they depart most widely from the ornithic type.

Clearly, then, the passage from Reptiles to Birds is not from the flying Reptile to the flying Bird. Let us try another line. I have already observed that, in the existing world, the nearest approximation to Reptiles is presented by certain land Birds, the Ostriches and their allies, all of which are devoid of the power of flight by reason of the small relative size of their fore-limbs and of the character of their feathers.

Can we find any extinct reptiles which approached these flightless birds, not merely in the weakness of their fore-limbs, but in other and more important characters?

I imagine that we can, if we cast our eyes in what at first sight seems to be a most unlikely direction.

The Dinosauria, a group of extinct reptiles, containing the genera Iguanodon, Hadrosaurus, Megalosaurus, Poikilopleuron, Scelidosaurus, Plateosaurus, etc., which occur throughout the whole series of the Mesozoic rocks, and are, for the most part, of gigantic size, appear to me to furnish the required conditions.

In none of these animals are the skull, or the cerrical region of the vertebral column, completely known, while the sternum and the manus have not yet been obtained in any of the genera. In none has any trace of a clavicle been observed.

With regard to the characters which have been positively determined, it has been ascertained, that :-

1. From four to six vertebræ enter into the composition of the sacrum, and become connected with the ilia in a manner which is partly ornithic, partly reptilian.

2. The ilia are prolonged forwards in front of the acetabulum as well as behind it, and the resemblance to the bird's ilium thus produced is greatly increased by the widely arched form of the acetabular margin of the bone, and the extensive perforation of the floor of the acetabulum.

I It will be understood that I do not suggest any direct affinity between Pterodactyles and Bats. 
3. The other two components of the os innominatum have not been observed actually in place; indeed, only one of them is known at all, but that one is exceedingly remarkable from its strongly ornithic character. It is the bone which has been called "clavicle" in Megalosaurus and Iguanodan by Cuvier and his successors, though the sagacious Buckland had hinted its real nature. ${ }^{1}$ But these bones are not in the least like the clavicles of any animal which possesses a clavicle, while they are extremely similar to the ischia of such a bird as an ostrich; and in the only instance in which they have been found in tolerably undisturbed relation with other parts of the skeleton, namely, in the Maidstone Iguanodon, they lie, one upon each side of the body, close to the ilia. I hold it to be certain that these bones belong to the pelvis, and not to the shoulder-girdle, and I think it probable that they are ischia; but I do not deny that they may be pubes.

4. The head of the femur is set-or at right angles to the shaft of the the bone, so that the axis of the thigh-bone must have been parallel with the middle vertical plane of the body, as in birds.

5. The posterior surface of the external condyle of the femur presents a strong crest, which passes between the head of the fibula and the tibia as in birds. There is only a rudiment of this structure in other reptiles.

6. The tibia has a great anterior or " procnemial" crest, convex on the inner, and concave on the outer, side. Nothing comparable to this exists in other reptiles, but a correspondingly developed crest exista in the great majority of birds, especially such as have great walking or swimming powers.

7. The lower extremity of the fibula is much smaller than the other ; it is, proportionally, a more slender bone than in other reptiles. In birds the distal end of the fibula thins away to a point, and it is a still more slender bone.

8. Scelidosaurus has four complete toes, but there is a rudiment of a fifth metatarsal. The third or middle toe is the largest, and the metatarsal of the hallux is much smaller at its proximal than at its distal end.

Iguanodon has three large toes, of which the middle is the longest, The slender proximal end of a first metatarsal has been found adherent to the inner face of the second, so that if the hallux was completely developed it was probably very small. No rudiment of the outer toe has been observed.

It is clear, from the manner in which the three principal metatarsals articulate together, that they were very intimately and firmly united, and that a sufficient base for the support of the body was afforded by the spreading out of the phalangeal regions of the toes.

From the great difference in size between the fore and hind limbs, Mantell, and more recently Leidy, have concluded that the Dinosauria (at least, Iguanodon and Hadrosaurus) may have supported them-

1 The so-called "coracoid" of Megalosaurus is the ilinm. I am indebted to Professor Phillips, and to the splendid collection of Megalosaurian remains which he hav formed at Oxford, for most important eridence touching this reptile. 
selves, for a longer or shorter period, upon their hind legs. But the discovery made in the Weald, by Mr Beckles, of pairs of large threetoed foot-prints, of such a size and at such a distance apart that it is difficult to believe they can have been made by anything but an Iguanodon, lead to the supposition that this vast reptile, and perhaps others of its family, must have walked, temporarily or permanently, upon its hind legs.

However this may be, there can be no doubt that the hind quarters of the Dinosauria wonderfully approached those of birds in their general structure, and therefore that these extinct Reptiles were more closely allied to birds than any which now live.

But a single specimen, obtained from those Solenhofen slates, to the accident of whose existence and usefulness in the arts palæontology is so much indebted, affords a still nearer approximation to the "missing link" between reptiles and birds. This is the singular reptile which has been described and named Compsognathus langipes by the late Andreas Wagner, and some of the more recondite ornithic affinities of which have been since pointed out by Gegenbaur. Notwilhstanding its small size (it was not much more than two feet in length), this reptile must, I think, be placed among, or close to, the Dinosauria; but it is still more bird-like than any of the animals which are ordinarily included in that group.

Compsognathus longipes has a light head, with toothed jaws, supported upon a very long and slender neck. The ilia are prolonged in front of and behind the acetabulum. The pubes seem to have been remarkably long and slender (a circumstance which rather favours the interpretation of the so-called "clavicles" of Iguanodon as pubes). The fore-limb is very small. The bones of the manus are unfortunately scattered, but only four claws are to be found, so that possibly each manus may have had but two clawed digits.

The hind limb is very large, and disposed as in birds. As in the latter class, the femur is shorter than the tibia, a circumstance in which Compsognathus is more ornithic than the ordinary Dinosauria.

The proximal division of the tarsus is ankylosed with the tibia, as in birds. In the foot the distal tarsals are not united with the three long and slender metatarsals, which answer to the second, third, and fourth toes. Of the fifth toe there is only a rudimentary metatarsal. The hallux is short, and its metatarsal appears to be deficient at its proximal end.

It is impossible to look at the conformation of this strange reptile and to doubt that it hopped or walked, in an erect or semi-erect position, after the manner of a bird, to which its long neck, slight head, and small anterior limbs must have given it an extraordinary resemblance.

I have now, I hope, redeemed my promise to show that, in past times, birds more like reptiles than any now living, and reptiles more like birds than any now living, did really exist.

But, on the mere doctrine of chances, it would be the height of improbability that the couple of skeletons, each unique of its kind, which have been preserved in those comparatively small: beds of 
Solenhofen slate, which record the life of a fraction of Mesozoic time, should be the relics, the one of the most reptilian of birds, and the other of the most ornithic of reptiles.

And this conclusion acquires a far greater force when we reflect upon that wonderful evidence of the life of the Triassic age, which is afforded us by the sandstones of Connecticut. It is true that these have yielded neither feathers nor bones; but the creatures which traversed them when they were the sandy beaches of a quiet sea, have left innumerable tracks which are full of instructive suggestion. Many of these tracts are wholly undistinguishable from those of modern birds in form and size; others are gigantic threetoed impressions, like those of the Weald of our own country ; others are more like the marks left by existing reptiles or Amphibia.

The important truth which these tracks reveal is, that, at the commencement of the Mesozoic epoch, bipedal animals existed which had the feet of birds, and walked in the same erect or semi-erect fashion. These bipeds were either birds or reptiles, or more probably both; and it can hardly be doubted that a lithographic slate of Triassic age would yield birds so much more reptilian than Archaooteryx, and reptiles so much more ornithic than Compsognathus, as to obliterate completely the gap which they still leave between reptiles and birds.

But if, on tracing the forms of animal life back in time, we meet, as a matter of fact, with reptiles which depart from the general type to become bird-like, until it is by no means difficult to imagine a creature completely intermediate between Dromaus and Compsognathus, surely there is nothing very wild or illegitimate in the hypothesis that the phylum of the class Aves has its root in the Dinosaurian reptiles; that these, passing through a series of such modifications as are exhibited in one of their phases by Compsognathus, have given riso to the Ratita; while the Carinata are still further modifications and differentiations of these last, attaining their highest specialization in the existing world in the Penguins, the Cormorants, the Birds of Prey, the Parrots, and the Song-birds.

However, as many completely differentiated birds in all probability existed even in the Triassic epoch, and as we possess hardly any knowledge of the terrestrial reptiles of that period, it may be regarded as certain that we have no knowledge of the animals which linked Reptiles and Birds together historically and genetically; and that the Dinosauria, with Compsognathus, Arehaopteryx, and the struthious Birds, only help us to form a reasonable conception of what these intermediate forms may have been.

In conclusion, I think I have shown cause for the assertion that the facts of Palæontology, so far as Birds and Reptiles are concerned, are not opposed to the doctrine of Evolution, but, on the contrary, are quite such as that doctrine would lead us to expect ; for they enable us to form a conception of the manner in which Birds may have been evolved from Reptiles, and thereby justify us in maintaining the superiority of the hypothesis, that birds have been so originated, to all hypotheses which are devoid of an equivalent basis of fact.

[T. H. H.] 


\section{II.-Mr. David Forbes on the Study of Chemtcal Geology.}

THEE Popular Science Review for July contains, among other 1 interesting matter, an excellent article, by Mr. David Forbes, F.R.S., on the Study of Chemical Greology.

The student, writes Mr. Forbes, who now-a-days intends to pursue the science of Geology with any chance of success, must not merely confine his labours to observation in the field, but must necessarily impose upon himself the task of acquiring at the same time a sound fundamental knowledge of the principles of several of the collateral sciences, in order that he may thereby be enabled to understand and estimate correctly, the true value of the evidence he may collect in his travels.

It was, doubtless, very different in the infancy of geology, when the name " geologist was applied to the observer, who, without any pretension to preliminary scientific knowledge, but endowed with a reasonable amount of common sense and a sturdy pair of legs, walked over the district in all directions with a map and section in his hand, upon which he coloured or noted down the relative extent, direction, and inclination of the various rocks which he encountered.

From its very nature, such work is, in great part, merely mechanical in character; and as it is well known that the best maps, whether geographical or geological, are not always the production of those most eminent in the higher branches of the sciences, it is not improbable that the intellectual powers required for the execution of such duties have occasionally been somewhat overrated.

In truth, the very existence of geology itself is dependent upon the co-operation of the allied sciences. Zoology came first to the assistance of the mere stratigrapher, and opened up a new and vast field of enquiry by insisting upon the value of palæontological evidence, and showing how sedimentary deposits, in even the most distant parts of the earth, might be co-related in geological chronology, a result which could never have been arrived at by the mere examination of their mineral character and position in the field; mathematics and astronomy lent their aid in solving many important problems connected with the phenomena of our sphere; and mineralogy was required to determine the mineral components of which its crust was formed; whilst a knowledge of optics and the use of the microscope enables the geologist to extend his investigations far beyond the limits to which his naked eye could otherwise convey him. ${ }^{1}$

When, however, the geologist advances further, and desires to study something more than the mere external forms and physical characters of the materials of which our globe is built up, he is compelled to call in the aid of chemistry, for it is by chemical science alone that he can be enabled to demonstrate the true nature of these materials, to explain their formation or origin, or to discover the causes which have produced the changes or alterations which they have already experienced, or which they may now be undergoing.

1 Vide "The Microscope in Geology," Popular Science Review, vol. vi., Oct. 1867, p. 355 , et seq. 
British geologists seem to have all but exclusively devoted themselves to the consideration of the stratigraphical and palæontological succession of the sedimentary beds, and have, as a rule, studiously avoided the investigation of all geological phenomena which did not appear to admit of explanation by the agency of mere mechanical forces. At the same time, however, it is curious to observe that there have not been wanting those who have put forth vague theories to account for the nature and formation of our metamorphic and eruptive rocks, etc., hypotheses which, unfortunately, can only be regarded as flights of imagination, since it is well known that, with but some few rare exceptions, no chemico-geological investigations or chemical analyses of British rocks or of their component minerals have as yet been made which could serve as a basis for any such generalisations.

Foremost as this country is in all the other departments of geology, Mr. Forbes considers Great Britain to be far behind in Chemical Geology.

The author cautions his readers against the innate tendency to take up a favourite cause or hypothesis, to which is often attributed effects in reality the result of some very different agency, or to the combined action of several causes; the student should, therefore, be particularly careful not to attach himself to any special theory or school of geology which might bias him when estimating the value of evidence brought forward on any question under consideration.

He then proceeds to point out the great importance of a careful definition of the terms igneous, aqueous, and gasolitic action, when applied to the study of geological phenomena.

1. Igneous action is the action of heat as seen developed in active volcanoes, the study of which led to the formation of the Plutonic school of geologists. This is not a mere dry fusion, like melting lead, glass, or other anhydrous substances in a crucible, but is one in which, whilst lieat plays the grand róle, is in nature invariably accompanied by the action of the vapour of water and gases.

2. Aqueous action is the action of waters (fresh or saline) such as are seen on the present surface of the globe; and is not the mere solvent action of pure water, but is one in which the air, gases, salts, and other bodies contained in natural waters, assisted by heat, materially alters the solvent powers and chemical reactions of the water itself.

3. Gasolitic action is the effect of gases and vapours, more or less assisted by heat.

All these agencies are naturally modified by the effects of chemical action and mechanical force. In all three cases, the actions of heat, of water, and of gases are found to be combined, each playing a more or less prominent part. Yet there can be no misunderstanding or confusing the precise meaning to be attached to each term.

In igneous or volcanic action, whilst the effects of heat predominate, the presence of heated steam and gases exercises a most important influence in modifying the results: and in this case the water present is in the form of steam. 
In aqueous action, on the other hand, the water acts as a liquid, not as a vapour, and is the main agency. Yet the effects of the gaseous and solid constituents, as well as of its temperature, must be taken into full consideration.

The immense volumes of steam emitted by volcanoes during their outbursts, would naturally prepare the observer to expect that some portion might become entangled in the lava, and thus account for the microscopic cavities containing water frequently found in volcanic products; whilst at the same time he would not consider the presence of microscopic water cavities in the older rocks as proving any dissimilarity of origin, or as necessarily demonstrating them to be of aqueous formation, as has been advanced by some writers on the subject.

As an illustration of the fact, that the same phenomenon may at times be the result of totally different agencies, Mr. Forbes takes, for example, the most widely spread of all substances, silica, and shows that it can be produced in the laboratory by many totally distinct processes : as an igneous product by the oxidation of silicon at high temperatures; as an aqueous product by the decomposition of silicates; as a gasolitic product from the decomposition of the gaseous compounds of silicon with fluorine, chlorine, etc.; and it even might be regarded as an organic product, when produced from the decomposition of the silicic ethers.

In the field the chemical geclogist meets with abundant cases of crystallised silica or quartz, as an igneous product occurring in the lavas from volcanoes; as an aqueous product crystallised from solution, or proceeding from the decomposition of mineral silicates; as a gasolitic product in the form of tubes, evidently resulting from the decomposition of its fluorine compounds; whilst the carapaces and other parts of infusoria, etc., present silica in a form which owes its appearance to the action of organic life.

Mr. Forbes concludes that it is impossible to be over-cautious in attributing the formation of minerals, or of the rock-masses in which they occur, to any one cause, to the exclusion of other agencies.

He roughly arranges all rocks which are as yet known, under two heads-eruptive and sedimentary; both of which classes of rocks can be subdivided respectively into normal and metamorphic, i.e. those which still are found comparatively ${ }^{1}$ unchanged, and those which have suffered metamorphism or alteration, brought about by either mechanical or chemical force, or by both combined.

The sedimentary strata, when comparatively unaltered, show themselves as tuffs, ashes, breccias, conglomerates, grits, sandstones, shales, clays, marls, limestones, etc., and have been all formed either by the direct destruction of eruptive rocks or of previous sedimentary beds which, in their turn, had so originated; even the lime which organic life has eliminated from the ocean to form the limestones, came, if not altogether, at least in greater part, from the same source. This has been the case even from the very oldest period, or, in other words, from the epoch of the consolidation of our sphere, since the

1 Everything in Nature appears, faster or slower, to become more or less altered. 


\section{Forbes-On the Study of Chemical Geology.}

original crust of the globe must be regarded as representing what may be termed the first eruptive or massive silicated rocks.

The study of the chemistry of the eruptive rocks, becomes, therefore, a subject of special interest and importance, not only as tending to elucidate their origin and formation, but also as bearing on the nature of the sedimentary strata which, as before mentioned, have, directly or indirectly, been formed from their ruins.

In Great Britain, it must be acknowledged, there is at this present time, little or no information on this subject in print; and of the few chemical analyses of rocks which have been published, it is to be feared that many of them have been made on specimens which have not been selected with care, so as to represent the actual rock-mass in question; and therefore such analyses, however accurately done, quite misrepresent the composition of the rock-mass as a whole; in fact, a lithological analysis is returned where a petrological analysis is required.

The terms lithology and petrology are continually misapplied and used for one another, notwithstanding that the difference between them is clearly indicated by their derivations; petrology from the Greek " $\pi$ étpos, a rock," ' being the study of rock masses in sitú, their relations, occurrence, origin, mineral character, physical structure, chemical composition, etc. ; whilst, on the other hand, lithology from " $\lambda(\theta o s$, a stone," is more properly applied to the consideration of stones or detached mineral masses not in sitú, blocks, boulders, pebbles, etc., such as are found in drift-gravel, alluvial formations, conglomerates, etc. A knowledge of lithology may be acquired in the cabinet, but petrology must of necessity be studied in the field.

The petrologist, by studying rock-masses on a large scale, discovers simplicity in cases where the lithologist would but eliminate confusion. By a careful examination of the rock in situ, assisted by the use of his microscope and laboratory, he comes to the conclusion that all the innumerable rock-species of the lithologist do not exist in nature as rocks, but are mere subordinate portions, altered in appearance or composition by subsequent influences.

Such alterations, or transitions as they are often called, are extremely common at the points of contact of sedimentary with eruptive rocks ; thus, for example, a Millstone grit or Carboniferous sandstone may, near the point of contact with an eruptive rock, be found to be lithologically quartzite, similar in appearance to some of even the most ancient quartzites, whilst petrologically considered, it is but sandstone. Again, a micaceous sandstone or a mica-schist bed may, at the point of contact with a felspathic exuptive rock, become in mineral composition a gneiss from the absorption of felspar, yet it is not so petrologically; the petrologist does not base his opinion upon mere hand-specimens, unless in the rare cases where they have been selected with judgment so as to represent the normal rock mass.

I Also $\pi \dot{\epsilon} \tau \rho a$, whence the synonym Petralogy. In the, for its time, very excellent treatise on rocks-Pinkerton's "Petralogy," 2 vols. London, 1811-the distinction between Lithology and Petralogy is fully explained. 
The backward state of petrological knowledge, especially as to the chemical and mineralogical composition of rocks, is in great measure due to the method pursued in its study : in general the field geologist, quite unacquainted with chemistry, and who most probably has never paid any attention even to the difference between petrology and lithology, on encountering a rock in the field knocks off any projecting corner or knob which may fall most convenient to his hammer, and sends it to the chemist for analysis. How far a geologist not versed in chemistry may be subsequently able to appreciate and utilise the results of the analysis returned to him by the chemist, is open to enquiry; but it may be safely predicted, that, either from proximity to neighbouring rocks of different character, or from the decomposition and alteration produced by atmospheric influences or weathering on all surface-rocks, that hand-specimens so collected are not likely to turn out correct representatives of the rock-mass as a whole.

When it is proposed to make a chemical examination of any particular rock, it should first of all be carefully studied in the field, in order that a correct opinion may be formed as to the true nature of the rock-substance itself, when uncontaminated or unchanged by external influences; a specimen may then be taken which, in some measure, will represent the actual rock-mass on the large scale, although this is attended with considerable difficulty and trouble, unless (as fortunately in England is generally the case) excavations or quarries have laid bare a face of rock, and so afforded facilities for obtaining the unaltered rock itself.

The quantity required to be taken and pulverised, in order to obtain an average for analysis, must entirely depend upon whether the rock is of a fine or coarse grained texture. In the latter case, a much larger quantity must naturally be employed.

All rock examinations should include a careful description of the mineral constituents of the rock itself, which, if fine-grained or compact, can only be effected by making a section and submitting it to the microscope. The physical properties, as specific gravity, etc., should also be noted, as well as, of course, the relations of the rock to the general geology of its district, and the occurrence of any accessory minerals disseminated in it.

It has been considered necessary to lay great stress upon all points connected with the selection and analysis of rocks, for, if these be not attended to, the labour bestowed upon them may be regarded as entirely thrown away. It cannot but be admitted that the possession of a series of accurate and trustworthy analyses of rocks is of almost vital importance to the advancement of Chemical Geology ; and it is sincerely to be hoped that, considering the backward state of our knowledge of this subject in England, some efforts will be made to remedy this defect, and so provide correct data for advancing further research into this promising department of geology. 
III.-A. Laganne.-Note sur les Érosions des Calcatres Dendodés de la Vallét de la Vézìre et de ses Afrudents. Ann. d'Agric., Sci., et Arts, Dordogne. (? 1868.) (Pp. 8.)

rTHIS short paper treats of the origin of the many channels that 1 furrow horizontally the limestones of the Valley of the Vézère, etc. These channels have been thought to be the result of old current-action, but M. Laganne shows that they have been formed.by atmospheric action, thereby confirming the opinion of $\mathrm{M}$. Lartet, and he thinks that frost is the principal, if not the only, agent employed.

The beds are mostly flat, but sometimes dip in the opposite direction to the flow of the neighbouring stream. In this latter case, if there is a bed susceptible of attack from atmospheric agents, the erosion of the channel follows that bed, and is therefore also in an opposite direction to the stream, whereas if the channel had been caused by current-action, it should clearly slope with the water-flow.

The weathering away of underlying yielding beds has often caused the fall of large masses of overlying firmer rock, and sometimes in places where currents could not possibly have caused such falls.

A means of measuring the rate of atmospheric denudation in the district is given by the occurrence of holes cut in the rock for the support of the rafters of old buildings of known age (about 1435), which were destroyed, exposing the rock in which the holes are cut to be acted on by the weather. Some of these holes are in a rock that does not yield to frost, and therefore are well preserved; others however, were cut in rock that weathers away more or less readily, and these have either wholly or partly disappeared. Assuming that all were once of about the same depth, as is most likely to have been the case, the rate of weathering is calculated to have been about 3-5ths of an inch in 20 years. This is a minimum for these rocks, as atmospheric agents act slowly on the bed in which the above observation was made.

The débris of the limestones form a talus sometimes many metres thick, which, on the current-theory, should have been carried away.

That the channels have not been caused by the chemical action of water, the anthor thinks is proved by the fact, that no beds of a kind that would result from such decomposition occur in the district. Moreover, chemical action would, he thinks, destroy the débris quicker than the solid rock. [Perhaps M. Laganne undervalues the chemical action of carbonated water, which surely must have had a large share in the wearing away of these limestones].

Lastly, the channels in question occur at all levels, and it is hard to suppose that the waters have been lowered, from the highest levels of the hills to their present level, so insensibly at to leave like traces on all parts of their downward course.

W. W. 


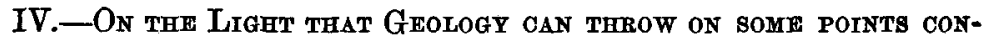 neCted with the Avcient History of the Athenians.}

By Albert Gaudry.

[Des lumières que la géologie peut jeter sur quelques points de l'histoire ancienne des Athéniens. Paris, $1867 . \mathrm{pp} .32$.

Extrait de l'ouvrage intitule-“" Animaux fossiles et géologie de l'Attique."]

$\mathrm{F}^{\circ}$ SSIL bones were known to the ancients, and the sight of these remains probably confirmed their belief in the fables of the transformation of living beings into stone. The Greeks had, under their eyes, instances of incrustations produced by the waters of regions composed of marble or compact limestone. Some have thought that the sight of fossil bones would have been regarded by the ancients as indications of the former existence of giants and other monsters. Since, however, it is admitted in our countries that man has been contemporaneous with several animals of extinct species, M. Gaudry inclines towards the opinion that these legends relating to gigantic beings have been based chiefly on the tradition of the animals that have been known in the living state. And it appears to him that the mythological animals of Pikermi have been imagined from a distant remembrance of living animals and not from the fossil bones.

That fossil shells were known to the ancients is, says M. Gaudry, without doubt, and this knowledge, in his belief, led them to adopt certain names for places in conformity with their former configuration, when a sight of these shells led them to such a conclusion; for instance, Peloponnesus (Isle of Pelops) was named for a country which in our days is no longer an island, and probably because the presence of the marine shells in the limestones of this isthmus of Corinth had revealed to them that where the isthmus is placed to-day there was formerly an arm of the sea forming a separation between Peloponnesus and the rest of Greece.

The division of Greece into little states, each possessing an independent position and maintaining a distinct character, resulted from the orographical disposition of the country.

Attica always had an " ungrateful soil." This agricultural poverty results from its geological constitution. Marbles are unfavourable to the development of vegetation; the mountain-chains where these rocks predominate are distinguished by their nudity, owing to the dryness which is due to the force with which they reflect the sun's rays. Travellers who have climbed the white marble mounts well know the burning character of these rocks. Moreover, the vegetable soil gets cemented by the infiltration of water containing bi-carbonate of lime.

The plains or valleys are usually occupied by loose mud and fragments of rocks brought down by torrents, not consolidated, so that the water sinks through and forms subterranean sheets which could furnish spring water.

Attica is well favoured for navigation. The isles of the Archipelago have contributed above all to the prosperity of Greece : they 
are, perhaps, the fragments of a vast continent which existed during the Miocene epoch ; when phenomena of depression marked the commencement of the Pliocene epoch, the lower parts of the continent were invaded by the sea and the higher points remained as islands.

The silver mines of Laurium are of great antiquity and note, but their mineral wealth is said to have been long ago exhausted. Workings are now established at Keratea to obtain the metals left in the refuse from the ancient workings.

The beautiful saccharoid marbles of Pentelicus and Paros have contributed in no small degree to the prosperity of Greece. The purity of the marbles inspired purity of execution. The quarries dug by the ancients are still to be seen, and many facts tend to show how particular they were, and to what expense they must have gone in order to procure the best stone.

M. Gaudry concludes with a few æesthetic and religious sentiments.

H. B. W.

\section{REVIFWS.}

I.-The Failure of Grological Attempts made by the Greits from the Earliest Ages down to the Epoch of Alexander. By Julius Schrarcz, F.G.S., President of the Hungarian Association for the Promotion of National Education, etc., etc. Revised and Enlarged Edition. London: Trübner and Co. 1868. pp. 153, 4to.

$\mathrm{D}^{\mathrm{n}}$

R. SCHVARCZ is well known in Hungary as a scholar of no mean pretensions, and his voice has long been uplifted in his native land in favour of national education. He is also deeply interested in Geology, and in all questions connected with its history from the earliest times.

We are so accustomed to consider Geology as the youngest of all the natural sciences, that we are, for the most part, content to date back its pedigree to the days of Werner, Cuvier, Desmarest, Hutton, Playfair, and William Smith, and to consider the works of earlier writers as belonging rather to the mythical part of its history-just as the Irish, Welsh, and Druidical legends are regarded. as compared with the modern history of our own country.

But the childhood of sciences, like that of nations, often affords to the student and historian matter for speculation of no mean interest.

Thus we find in the sacred books of the Hindoos, passages, which, though veiled in poetic or mystic language, seem to indicate considerable advance both in a knowledge of astronomy and physical geology.

The learned too among the Chinese and Eyytians, cultivated habits of observation, and noted many changes in the condition of land-and sea-surfaces, and other physical phenomena, which relate more or less directly to natural science.

But even in awarding to these, the most favourable degree of merit 